\title{
Clinico-Radio-Pathological and Molecular Features of Hepatocellular Carcinomas with Keratin 19 Expression
}

\author{
Hyungjin Rhee $^{\mathrm{a}} \quad$ Haeryoung Kim $^{\mathrm{b}}$ Young Nyun Park ${ }^{\mathrm{c}}$ \\ aDepartment of Radiology, Research Institute of Radiological Science, Center for Clinical \\ Imaging Data Science, Severance Hospital, Yonsei University College of Medicine, \\ Seoul, Republic of Korea; bDepartment of Pathology, Seoul National University Hospital, \\ Seoul National University College of Medicine, Seoul, Republic of Korea; 'Department of \\ Pathology, Brain Korea 21 PLUS Project for Medical Science, Yonsei University College of \\ Medicine, Seoul, Republic of Korea
}

\section{Keywords}

Keratin 19 - Hepatocellular carcinoma - Invasiveness - Treatment resistance - Poor prognosis

\begin{abstract}
Hepatocellular carcinoma (HCC) is a heterogeneous neoplasm, both from the molecular and histomorphological aspects. One example of heterogeneity is the expression of keratin 19 (K19) in a subset (4-28\%) of HCCs. The presence of K19 expression in HCCs has important clinical implications, as K19-positive HCCs have been associated with aggressive tumor biology and poor prognosis. Histomorphologically, K19-positive HCCs demonstrate a more infiltrative appearance, poor histological differentiation, more frequent vascular invasion, and more intratumoral fibrous stroma than K19-negative conventional HCCs. From the molecular aspect, K19-positive HCCs have been matched with various gene signatures that have been associated with stemness and poor prognosis, including the G1-3 groups, S2 class, cluster A, proliferation signature, and vascular invasion signature. K19-positive HCCs also show upregulated signatures related to transforming growth factor- $\beta$ pathway and epithelial-to-mesenchymal transition. The main regulators of K19 expression include hepatocyte growth factorMET paracrine signaling by cancer-associated fibroblast, epidermal growth factor-epidermal growth factor receptor signaling, laminin, and DNA methylation. Clinically, higher serum alpha-fetoprotein levels, frequent association with chronic hepatitis $B$, more invasive growth,
\end{abstract}

Hyungjin Rhee and Haeryoung Kim contributed equally. 
and lymph node metastasis have been shown to be characteristics of K19-positive HCCs. Radiologic features including atypical enhancement patterns, absence of tumor capsules, and irregular tumor margins can be a clue for K19-positive HCCs. From a therapeutic standpoint, K19-positive HCCs have been associated with poor outcomes after curative resection or liver transplantation, and resistance to systemic chemotherapy and locoregional treatment, including transarterial chemoembolization and radiofrequency ablation. In this review, we summarize the currently available knowledge on the clinico-radio-pathological and molecular features of K19-expressing HCCs, including a detailed discussion on the regulation mechanism of these tumors.

(C) 2020 The Author(s)

Published by S. Karger AG, Basel

\section{Introduction}

Hepatocellular carcinoma (HCC) is the 4th leading cause of cancer-related mortality worldwide, and its prognosis is generally poor [1]. While HCC is defined simply as a primary malignant neoplasm with hepatocellular differentiation [2], accumulating data in the past few decades has indicated that HCC is a heterogeneous neoplasm, both from the molecular and histomorphological points of view. An example of heterogeneity in HCC is the presence of keratin 19 (K19) expression.

Keratins are intermediate filaments, consisting of heteropolymers of acidic, lower molecular weight type I keratins and basic, higher molecular weight type II keratins; K19 is the smallest (approximately $40 \mathrm{kDa}$ ) type I keratin and lacks a tail domain [3]. In the normal liver, mature hepatocytes express K8 and K18, while cholangiocytes and hepatic stem/ progenitor cells additionally express K7 and K19 [4]. Therefore, K19 can be a marker of hepatic stem/progenitor cell, as well as a marker of cholangiocytic differentiation. Approximately, 4-28\% of HCCs have been reported to express K19 [5-9].

HCCs with K19 expression have been associated with unique pathological, molecular, genetic, and microenvironmental characteristics; an aggressive biological nature; and a poor prognosis. K19 expression status has also been incorporated into the more recently proposed molecular classifications of HCC, including "S2" by Hoshida et al. and "G1-3" groups by Boyault et al. In addition, KRT19 mRNA expression is part of the "5-gene score" proposed by Nault et al. [10-13]. In vitro studies have also demonstrated that K19-positive HCC cells harbor cancer stem cell characteristics, such as self-renewal, differentiation into K19-negative cells, generation of highly proliferative HCCs, and chemoresistance [14]. Therefore, K19 is considered as a prognostic marker for HCC, and this has been stated in the 4th and 5th editions of the WHO Classification of Tumors of the Digestive System [2,15]. K19 expression is also a marker for resistance to systemic chemotherapy and locoregional treatment, including transarterial chemoembolization (TACE) and radiofrequency ablation (RFA) $[8,9,14,16]$. In this review, we discuss comprehensively the clinico-radio-pathological and molecular features of K19-expressing HCCs and their regulation mechanism.

\section{Clinicopathological Features of HCCs with K19 Expression}

HCC with K19 expression is defined as HCC that demonstrates substantial (in $>5 \%$ of tumor cells) immunohistochemical expression of K19 [2]. HCCs with K19 expression have been associated with high serum alpha-fetoprotein levels, chronic hepatitis B, and a more aggressive behavior, including decreased overall and recurrence-free survival, than K19-negative HCCs [5, 7-9].

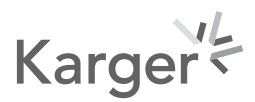



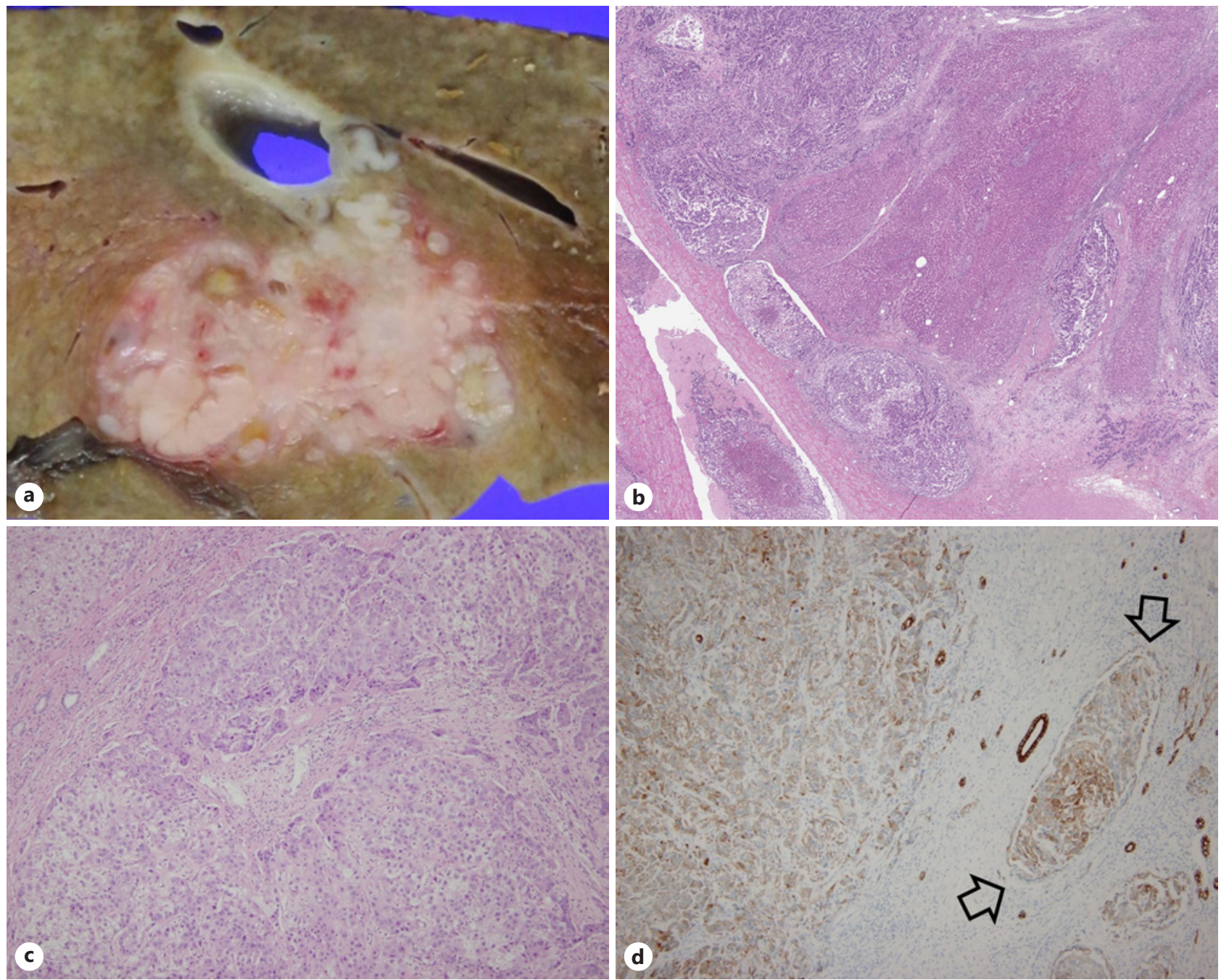

Fig. 1. Morphological features of K19-expressing HCCs. An infiltrative growth pattern is seen on both macroscopic (a) and microscopic (b) examination. Frequent vascular invasion (b) and intratumoral fibrous stroma (c) are also features of these tumors. d K19 expression in the tumor cells. Portal vein invasion is marked by arrows. b, c Hematoxylin-eosin. d immunohistochemistry for K19; original magnification, $\times 10$ (b), $\times 100$ (c, d). K19, keratin 19; HCC, hepatocellular carcinoma.

The following histopathological features have been frequently observed in K19-positive HCCs. K19-positive HCCs are less frequently encapsulated and show a more infiltrative appearance [7, 17, 18] (Fig. 1a, b). More frequent vascular invasion, including portal vein invasion, has been observed in K19-positive HCCs (Fig. 1b). Extrahepatic dissemination is common in K19-positive HCCs, including lymph node metastases as well as pulmonary metastases $[8,16,19]$. Thus, invasiveness is one of the key features of K19-positive HCCs, and the functional connection between K19 expression and invasiveness has been demonstrated in in vitro models $[8,20]$.

The tumor microenvironment of K19-positive HCCs is characterized by fibrotic tumor stroma; therefore, the microscopical picture of K19-positive HCCs may overlap with that of scirrhous HCCs (Fig. 1c). Scirrhous HCC is an HCC variant with abundant intratumoral fibrous stroma that occupies $30-50 \%$ of the tumor area [21, 22]. In fact, the majority of scirrhous HCCs express K19 or other stemness-related markers. Hence, K19-positive and scirrhous 


\section{Liver Cancer}

Liver Cancer 2020;9:663-681

DOI: $10.1159 / 000510522$

Rhee et al.: Characteristics of Hepatocellular Carcinomas with Keratin 19 Expression
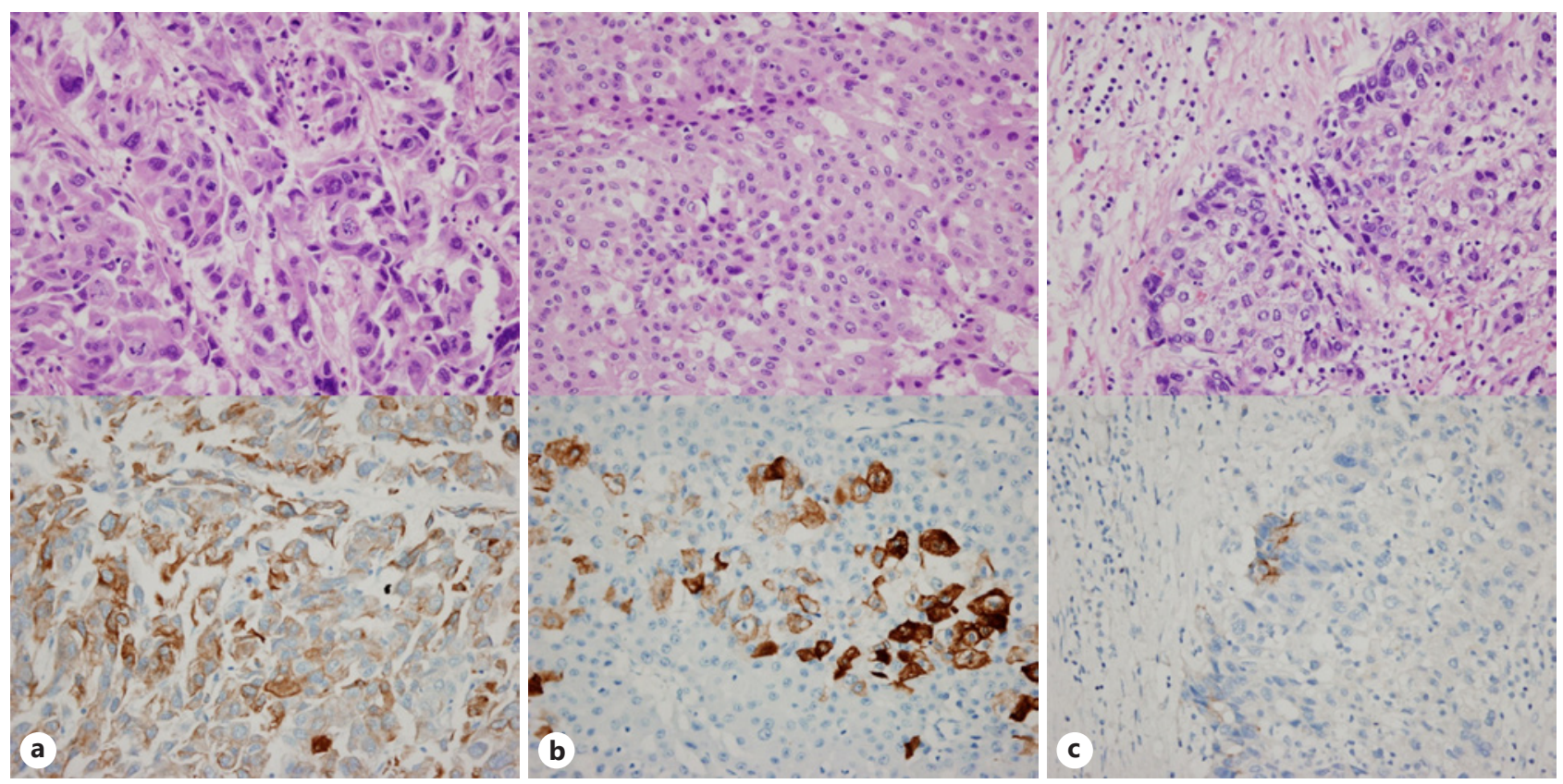

Fig. 2. Morphological features of K19-expressing HCCs. K19-expressing HCC cells are frequently poorly differentiated (a); however, those with lower histological grade may also express K19 (b). K19 expression is also frequently observed in the smaller "hepatic progenitor cell-like" tumor cells at the periphery of tumor nests, facing the fibrous stroma (c) (upper row: hematoxylin-eosin, lower row: immunohistochemical stain for K19; original magnification, ×400). K19, keratin 19; HCC, hepatocellular carcinoma.

HCCs may lie on the same spectrum of HCCs, with the latter containing more intratumoral fibrous stroma [7, 22]. While the prognosis of scirrhous HCC in relation to conventional HCC is still controversial, associations between scirrhous HCC and decreased survival have been demonstrated, especially in HCCs larger than $5 \mathrm{~cm}$ [22]. Interestingly, in contrast to that of fibrolamellar HCC - another subtype of HCC that demonstrates DNAJB1-PRKACA gene fusion and is also characterized by abundant fibrous stroma - the fibrous stroma of scirrhous HCC contains more abundant cancer-associated fibroblasts (CAFs) and tumor-infiltrating macrophages, suggesting a possible role of this complex tumor microenvironment in the aggressive behavior of scirrhous HCC [23]. In addition, K19 expression has been less frequently noted in fibrolamellar HCC than scirrhous HCC [23].

K19 positivity in HCCs has been associated with poor histological differentiation; however, within the tumor, K19 expression can either be diffuse or be patchy, and the tumor cells that label for K19 may show lower histological grade (Fig. 2) [7]. Moreover, K19 positivity does not seem to have a predilection for a particular morphological phenotype of tumor cell: K19 may be expressed in HCC cells with or without hepatic stem/progenitor cell-like morphology [7]. Frequent K19 expression has also been observed in the recently described macrotrabecular-massive subtype of HCC, which is characterized by a macrotrabecular architecture ( $>6$ cells thick) that occupies the majority of the tumor area [13].

K19-positive HCCs also frequently express other markers associated with stemness, such as epithelial cell adhesion molecule (EpCAM), CD133, and c-kit/CD117. However, when the expression status of stemness-related markers were correlated in HCCs, K19 expression was most frequently found in combination with the expression of at least one other stemnessrelated marker, and K19 expression status was more closely related to the aggressive behavior of HCC compared to the expression status of other stemness-related markers [7].

\section{Karger'}


From the diagnostic perspective, it should be noted that although K19 is considered a marker of cholangiocytes or hepatic stem/progenitor cells, the expression of K19 per se in HCCs does not qualify these tumors to be diagnosed as combined hepatocellular-cholangiocarcinomas (cHCC-CCAs) unless histological features of intrahepatic cholangiocarcinoma (iCCA) are unequivocally present [24]. In addition, K19-positive HCCs are different from intermediate carcinomas, which show features intermediate between those of hepatocytes and cholangiocytes in terms of both cytomorphology and immunoprofile [25].

\section{Molecular Features and Tumor Microenvironment of HCCs with K19 Expression}

Recent advances in genome-wide profiling technology have enabled the characterization of molecular alterations in HCC and the identification of its various gene signatures. The CK19 human and rat gene signatures have been associated with K19 expression in HCC, and in human and rat models, respectively, and with poor survival [26, 27]. Other transcriptomicsbased gene expression profiling studies have identified gene signatures related to hepatic progenitor cells, such as the hepatoblastoma C2, EpCAM, and CCA-like signatures [28-30]. In addition, "cluster A," "G1-3 class," "proliferation signature," "transforming growth factor- $\beta$ (TGF- $\beta$ ) signature," "MET signature," "vascular invasion signature," and "S2 class" have also been found to be correlated with CK19 human/ratsignatures, again emphasizing the biological significance of K19 expression in HCCs [10, 11, 31-36]. A recent multi-platform molecular analysis of HCCs demonstrated 3 major subtypes of HCCs, of which one major subtype comprised stem cell-like tumors [37]. This subtype demonstrated increased expression of genes involved in mitosis, increased chromosomal instability, poor differentiation, portal vein invasion, advanced tumor stage, and decreased overall and disease-free survivals, and these features were further validated in The Cancer Genome Atlas cohort [37]. In terms of the tumor microenvironment, the immunological expression profile of this subtype of HCC corresponded to that of the "C1/C2 (wound healing/IFN $\gamma$ dominant)" subclass, characterized by increased mitogenic activity and chromosomal instability [37]. In another classification proposed by The Cancer Genome Atlas, HCCs with "IDH-like gene expression" or IDH1/2 mutations formed a subset of a poor prognosis group, "iCluster1," and demonstrated hepatic stem cell-like features [38]. Accordingly, the appearance of stemness features in most of the proposed HCC classifications further supports the robustness of stemness as an important prognostic marker for HCC and the usefulness of K19 as a prognostic marker in HCC tissues.

Detailed information regarding the immune landscape of HCC has become available over the past few years. An "immune class" of HCC has been identified by Sia et al. [39], which constitutes about $25 \%$ of HCCs, and this has been further divided into 2 subclasses: "exhausted immune response" and "active immune response." Although K19 expression status or stemness has not been directly addressed in this study, it is interesting that the "exhausted immune response" subclass of HCCs was characterized by features demonstrated in K19-positive HCCs, such as TGF- $\beta$ signaling pathway activation, M2 macrophage infiltration, enrichment of pathways related to epithelial-to-mesenchymal transition (EMT), and metastasis $[14,39]$. Another study extensively explored the immune microenvironment of HCC by a multiplex immunohistochemistry approach and classified HCCs as "immune-high," "immunemid," and "immune-low" subtypes, based on the types of infiltrated immune cells [40]. The immune subtypes were correlated with the histopathological and molecular classifications of HCCs, and the "immune-high" group was characterized by increased B-cell, plasma cell, and T-cell infiltration, where the percentage of HCCs with stemness marker expression (K19 and/ or Sal-like protein 4 [SALL4], designated as "biliary/stem-1 subclass" by the authors) is relatively higher than that of those with non-"biliary/stem-1 subclass" HCCs (e.g., $\beta$-catenin/Wnt

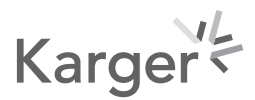


type), accounting for approximately 20\%. Interestingly, among the K19 and/or SALL4positive HCCs, the presence of an "immune-high" microenvironment was associated with a favorable prognosis compared to stemness-related HCCs with "immune-mid/low" microenvironments [40]. Taken together, it appears that there is heterogeneity in the immune microenvironment of K19-positive HCCs.

Associations between K19-positive HCCs and EMT have been demonstrated in both human tissues and cell lines. A recent in vitro study demonstrated greater cell motility and upregulation of TGFßR1, SNAI1, SNAI2, and VIM expression in K19-positive Huh7 cells, suggesting a role for K19 expression in EMT and TGF- $\beta$ signaling pathway activation [14]. Interestingly, a "vessels-that-encapsulate-tumor-clusters (VETC)"-type vascular pattern has recently been identified in a subset of HCCs, in which tumor cell clusters are coated by vascular endothelial cells; these vascular endothelium-coated HCC clusters enter the circulation and give rise to hematogenous metastasis, independent of EMT [41]. Although this VETC pattern has been linked with aggressive behavior in HCC, an association between VETC pattern and K19 expression has not been demonstrated, and it is likely that K19-positive HCCs metastasize via an EMT-dependent mechanism [14, 42]. In addition, longer telomeres, increased telomerase activity, and higher expression of telomerase reverse transcriptase, together with increased chromosomal instability, have been detected in K19-positive HCCs [43, 44]. These findings suggest that K19-expressing HCCs may be at an advantage for survival and further progression compared to K19-negative HCCs, by maintaining telomeres despite the increased chromosomal instability [43].

\section{Regulation Mechanism of K19 Expression in HCC}

In the past, a hepatic stem/progenitor cell origin was postulated for K19-positive HCCs, based on the immunohistochemical marker expression status [4, 5]. However, the marker profile of a tumor does not necessarily predict its cell of origin. Smaller HCC cells that morphologically resemble hepatic stem/progenitor cells often express K19, but these cells are not always observed in K19-positive HCCs, and K19 may in fact be expressed in tumor cells that do not have a hepatic stem/progenitor cell-like morphology [7]. Several recent studies using lineage-tracing rodent HCC models demonstrated that K19-positive HCC cells originate from mature hepatocytes, and not from hepatic stem/progenitor cells [45, 46]. In addition, K19-positive HCC cells were not observed in the early clonal expansion of rodent hepatocarcinogenesis [47]. In human multistep hepatocarcinogenesis, the expression of stemnessrelated markers was rarely observed in dysplastic nodules (a precancerous lesion) and well differentiated early HCCs. However, a gradual increase in K19 expression was observed in moderately and poorly differentiated advanced HCCs, together with a gradual enrichment of fibrous stroma [48]. Although the possibility of a stem/progenitor cell origin for K19-positive HCCs cannot be completely excluded, these findings indicate that the majority of K19-positive HCCs develop in the later stages of hepatocarcinogenesis by clonal selection. Recently, K19 expression in HCC has been shown to be regulated by microenvironmental and epigenetic mechanisms, and the details are summarized below (Fig. 3).

\section{Hepatocyte Growth Factor-MET Paracrine Signaling by CAFs}

Keratin synthesis is mostly regulated at the transcriptional level and is modulated by diverse external signals, including growth factors, cytokines, hormones, and vitamins [49]. As previously mentioned, K19-positive HCCs have abundant fibrous stroma containing CAFs, and are therefore subject to a variety of paracrine signals originating from the fibrous stroma. Moreover, the tumor cells of scirrhous HCCs have a biphasic appearance, with polygonal,

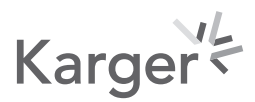




\begin{tabular}{|c|c|c|}
\hline & \multicolumn{2}{|c|}{ Liver Cancer 2020;9:663-681 } \\
\hline Liver Cancer & DOI: $10.1159 / 000510522$ & $\begin{array}{l}\text { (c) } 2020 \text { The Author(s). Published by S. Karger AG, Base } \\
\text { www.karger.com/lic }\end{array}$ \\
\hline
\end{tabular}

Rhee et al.: Characteristics of Hepatocellular Carcinomas with Keratin 19 Expression

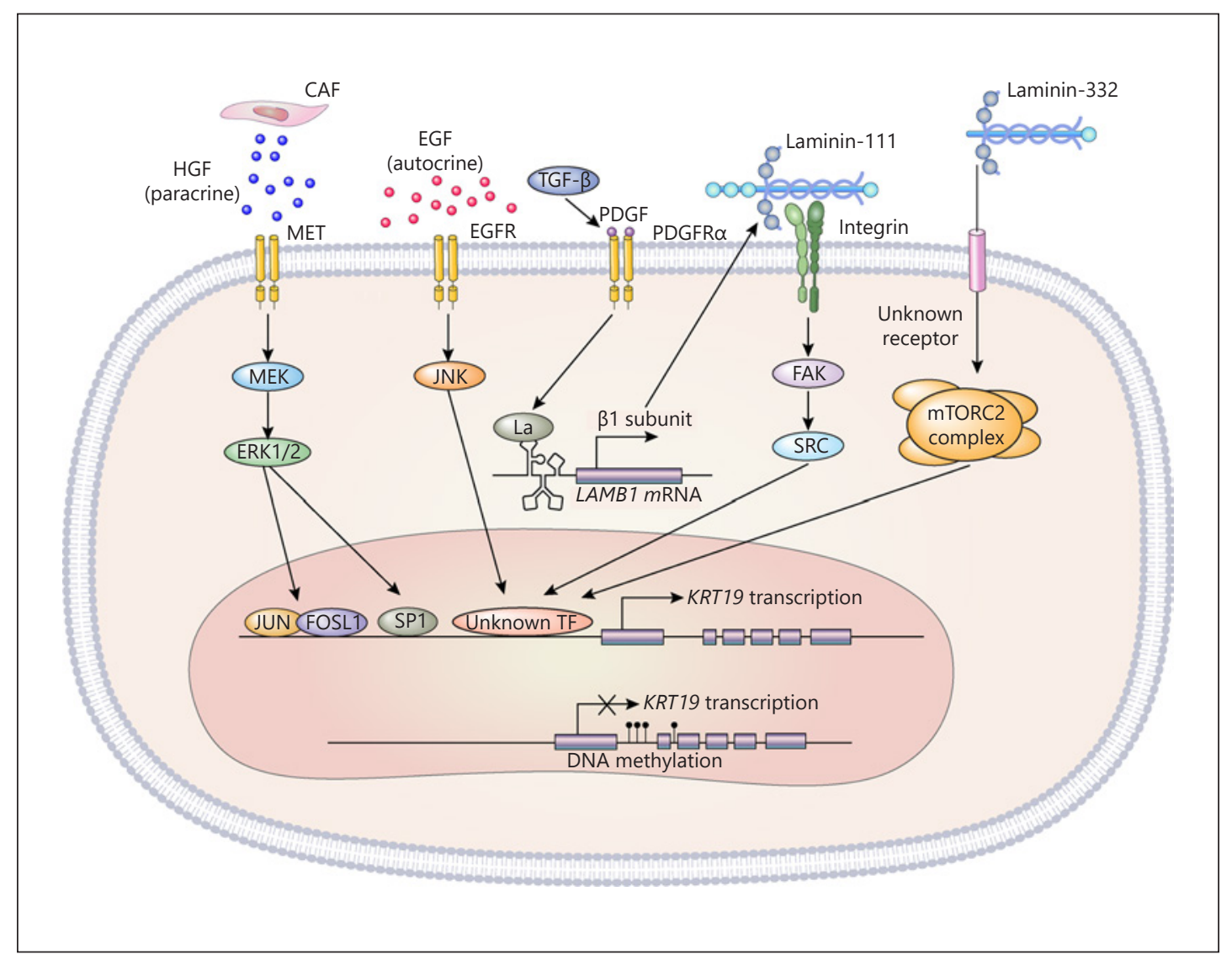

Fig. 3. Regulatory mechanism of KRT19 expression in HCC. Expression of KRT19 is regulated at the transcriptional level by various external signals. HGF secreted from CAF activates the MET-MEK-ERK1/2 pathway and transcriptional factors JUN/FOSL1 and SP1 which upregulate KRT19 transcription. EGF secreted from HCC cells also acts in an autocrine manner to upregulate KRT19 through the EGFR-JNK pathway and unknown TF. Laminins also play an important role in KRT19 regulation. Laminin-332 and laminin-111 upregulate KRT19 through the mTORC complex and the integrin-FAK-SRC pathway, respectively. Epigenetic regulation of KRT19 is also important for KRT19 expression; the dense methylation of the KRT19 promoter decreases the expression of KRT19. HGF, hepatocyte growth factor; CAF, cancer-associated fibroblast; EGF, epidermal growth factor; FAK, focal adhesion kinase; TF, transcription factor; JNK, Jun N-terminal kinase; EGFR, epidermal growth factor receptor; HCC, hepatocellular carcinoma.

mature hepatocyte-like cells in the center of the tumor cell nests and smaller "hepatic progenitor cell-like" cells that frequently express K19 at the tumor-stromal interface. This topographical relationship suggests there is cross talk at the tumor-stromal interface, between tumor epithelial cells with stemness and CAFs [22]. Hepatocyte growth factor, secreted by CAFs, activates MET in tumor epithelial cells and subsequently activates the MEK-ERK1/2 signaling pathway and its downstream transcription factors (SP1 and heterodimer of JUN and FOSL1), leading to the upregulation of KRT19 transcription (Fig. 3) [50]. Hepatocyte growth factor-MET signaling has both mitogenic and motogenic properties and plays an important role in the invasive growth of both non-tumoral stem cells and cancer cells [51,52]. The MET signature has also frequently been observed in K19-positive HCCs, supporting the invasive biological characteristics of these HCCs $[36,50]$. 


\begin{tabular}{ll|l}
\cline { 2 - 2 } Liver Cancer 2020;9:663-681 \\
\cline { 2 - 2 } & DOl: 10.1159/000510522 & $\begin{array}{l}\text { @ } 2020 \text { The Author(s). Published by S. Karger AG, Basel } \\
\text { www.karger.com/lic }\end{array}$ \\
\cline { 2 - 3 }
\end{tabular}

Rhee et al.: Characteristics of Hepatocellular Carcinomas with Keratin 19 Expression

\section{Epidermal Growth Factor-Epidermal Growth Factor Receptor Signaling}

Epidermal growth factor (EGF), secreted by HCC cell lines, has been demonstrated to induce KRT19 transcription via the epidermal growth factor receptor (EGFR)-c-Jun N-terminal kinase (JNK) pathway and increase the proliferative and invasive properties of HCC cells [53]. The expression of EGF, EGFR, and JNK proteins was also significantly more frequent in K19-positive HCCs than in K19-negative HCCs, suggesting that the EGF-EGFR signaling axis may play an important role in the acquisition of stemness in HCC [53].

\section{Laminin-111 and Laminin-332}

Laminin, together with myofibroblasts and macrophages, has been reported to constitute an important niche for maintenance of progenitor cells. Laminin was reported to be found in basement membranes surrounding the hepatic stem/progenitor cells in nonneoplastic liver [54]. Hepatic stellate cells and sinusoidal endothelial cells contribute to the synthesis of laminin $[55,56]$. In a transcriptomic analysis study, the gene expression of $L A M B 1$ and $L A M C 2$ was reported to be significantly higher in K19-positive HCC than that in K19-negative HCC, suggesting that laminin might affect K19 expression [8]. LAMB1 is a gene that encodes the $\beta 1$-chain of laminin-111. The expression of laminin-111 is increased in response to TGF- $\beta$, by increased translation of LAMB1 via PDGFR $\alpha$-La/SSB signaling [57]. Laminin-111, in turn, acts in an autocrine manner to upregulate K19 gene expression through focal adhesion kinaseSRC signaling [58]. LAMC2 is a gene that encodes the $\gamma 2$-chain of laminin-332. Laminin-332 was observed to be expressed in small hepatic progenitor cell-like tumor cells in HCC, and it increased K19 expression in HCC cell lines in an mTORC2-dependent manner [59]. In HCCs, the expression of laminin-111 and laminin-332 was reported to be frequently observed in those with K19 expression, and in tumor cells at the invasion fronts [58-60].

\section{DNA Methylation of the K19 Promoter}

Inhibition of DNA methyltransferase-1 has been reported to increase the expression of various stemness-related genes (including KRT19) in a side population of HCC cell lines [61]. In addition, KRT19 promoter methylation was recently reported to be significantly associated with K19 expression in HCC cells, indicating an important role of epigenetic regulation of K19 [62].

\section{Evaluation of K19 Expression in the Tissue and Serum of Patients with HCC}

It is not possible to diagnose K19-positive HCC by histomorphological evaluation alone based on hematoxylin-eosin-stained slides. Detection of K19 protein expression is required for the diagnosis of K19-positive HCC. K19 protein expression is usually detected by immunohistochemistry on formalin-fixed paraffin-embedded tissues. Although K19 expression in HCC is usually patchy rather than diffuse, we found that the evaluation of K19 expression in small biopsied HCC tissue was comparable to that in matched resected HCC: the sensitivity, specificity, and accuracy of K19 detection in biopsied tissue were found to be 80,88 , and $86 \%$, respectively, when that of matched resection tissue was used as a reference standard [63]. Therefore, evaluation of K19 status in biopsied HCC tissue is considered a reliable method of identifying K19-expressing HCCs.

There are a large number of commercially available K19 antibodies that target various epitopes, of which RCK108 and BA17 are most commonly used. The epitope of the RCK108 antibody is closer to the $\mathrm{N}$-terminus of $\mathrm{K} 19$, between amino acid residues 112 and 153, while the epitope of the BA17 antibody is in the C-terminal region of K19, between amino acid residues 360 and 395 [64]. The immunoreactivities of the 2 abovementioned antibodies are

\section{Karger ${ }^{\prime \prime}=$}


closely correlated; however, discordance in the staining proportion and intensity has been reported in breast cancer and pancreatic neuroendocrine tumors $[65,66]$. Nevertheless, K19-positive HCCs defined by the RCK108 antibody [5, 7, 8] and those defined by the BA17 antibody $[9,20]$ demonstrated similar characteristics, including higher serum alpha-fetoprotein levels, more frequent vascular invasion, and poor prognosis.

Several less-invasive serum-based methods have also been developed, as liver biopsy is not routinely performed for HCC patients according to the current guidelines [67-69]. CYFRA21-1 is a soluble fragment of K19, the concentration of which is determined using 2 monoclonal antibodies, KS 19.1 and BM 19.21 [70]. CYFRA21-1 has been reported as a prognostic biomarker non-small cell lung cancer [71]. Among the primary liver cancers, high serum CYFRA21-1 levels have been observed in patients with iCCA; hence, the serum CYFRA21-1 level is considered a potential diagnostic marker of iCCA [72]. Approximately $22-47 \%$ of HCCs are associated with increased serum CYFRA21-1 levels, and high serum CYFRA21-1 level has been associated with K19 expression in HCC [73-76]. In addition, high CYFRA21-1 levels were found to be associated with portal vein thrombosis, larger tumor size, and higher TNM stage in HCC [77]. However, no prognostic differences according to serum CYFRA21-1 levels have been found [76, 77]. Therefore, there is only limited evidence for the clinical significance of CYFRA21-1 in HCC patients, and additional studies on large-scale cohorts are needed.

Another recently proposed method for the noninvasive detection of K19 expression in HCC is KRT19 mRNA quantification in circulating tumor cells. Choi et al. [78] compared the KRT19 mRNA levels in circulating tumor cells before and after resection of HCC and found that the ratio of postoperative to preoperative KRT19 mRNA levels was significantly associated with HCC recurrence after surgical resection. As K19-positive circulating cells could originate from both non-tumor liver and HCC, the change in KRT19 mRNA levels between the preoperative and postoperative stages might be a better marker for K19-positive circulating tumor cells and postsurgical outcome.

\section{Radiologic Features of K19-Positive HCC}

The imaging findings associated with K19-positive HCCs have been reported in several studies using gadoxetic acid-enhanced MRI, computed tomography (CT), and ${ }^{18}$ F-FDG PET [79-84].

Dynamic Enhancement Patterns and Radiologic Morphology of K19-Positive HCC

The imaging "hallmark" of HCC is arterial phase hyperenhancement with washout in the portal venous phase image of multiphase CT or MRI; this is the diagnostic feature for patients with high risk of HCC $[85,86]$. In contrast, K19-positive HCCs often show atypical enhancement patterns, including weaker arterial phase hyperenhancement, arterial phase rim-like enhancement, and gradual enhancement in the portal venous and delayed dynamic phases (Fig. 4a-c) [80-82, 84]. While these atypical enhancement patterns are considered obstacles to an imaging diagnosis of HCC, they may - on the other hand - serve as clues to the diagnosis of HCCs with K19 expression.

The atypical enhancement patterns may be explained by the following histopathological features of K19-positive HCC. HCCs with abundant fibrous stroma have been frequently associated with rim-like arterial enhancement, absence of washout, gradual enhancement, and delayed central enhancement of the tumor [87]. As an abundance of fibrous stroma is one of the histopathological characteristics of K19-positive HCC, it is understandable that K19-positive HCC often exhibits atypical enhancement [7, 22, 50, 80]. Delayed contrast media

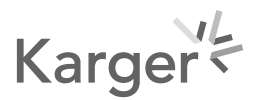



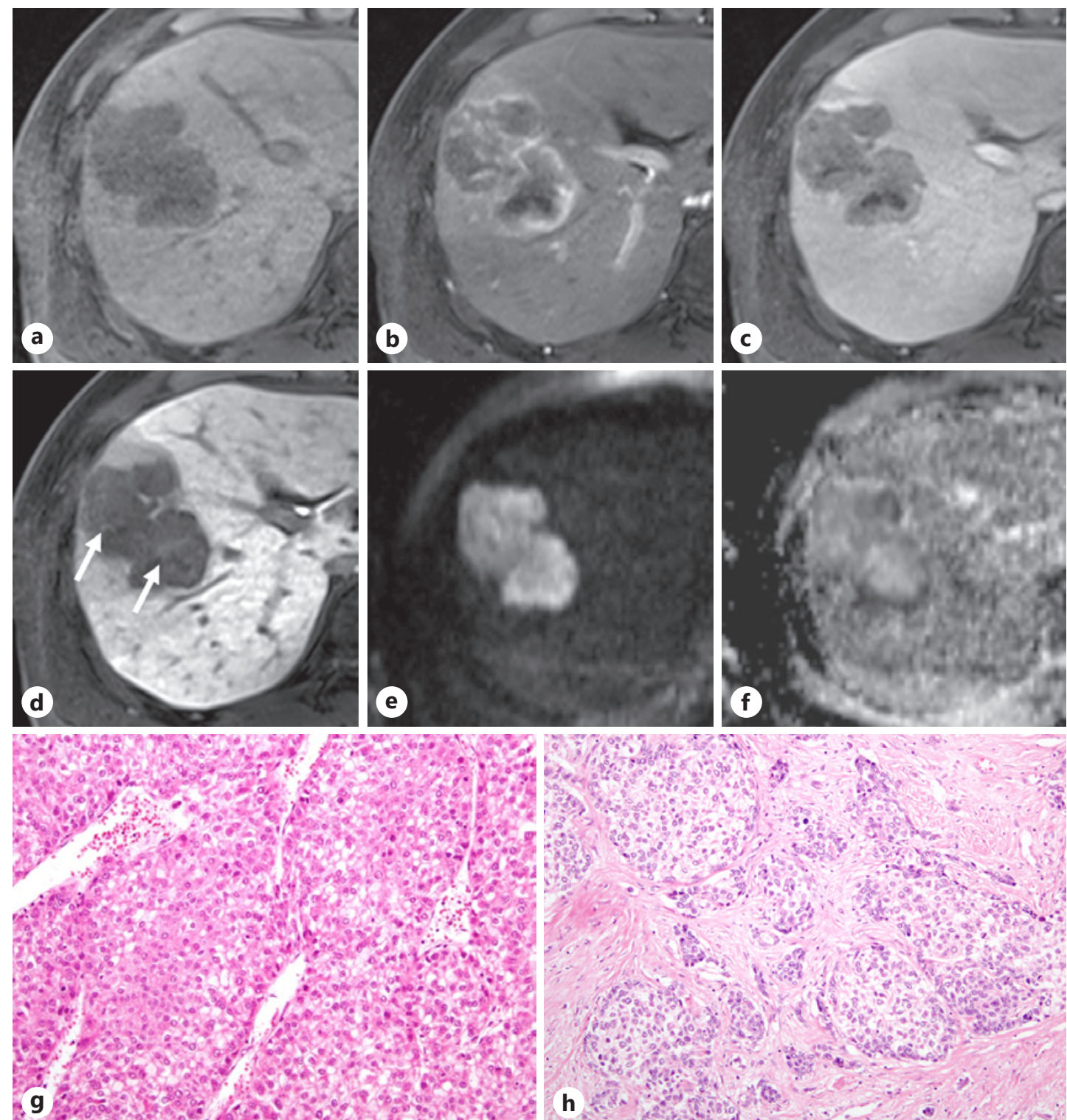
9
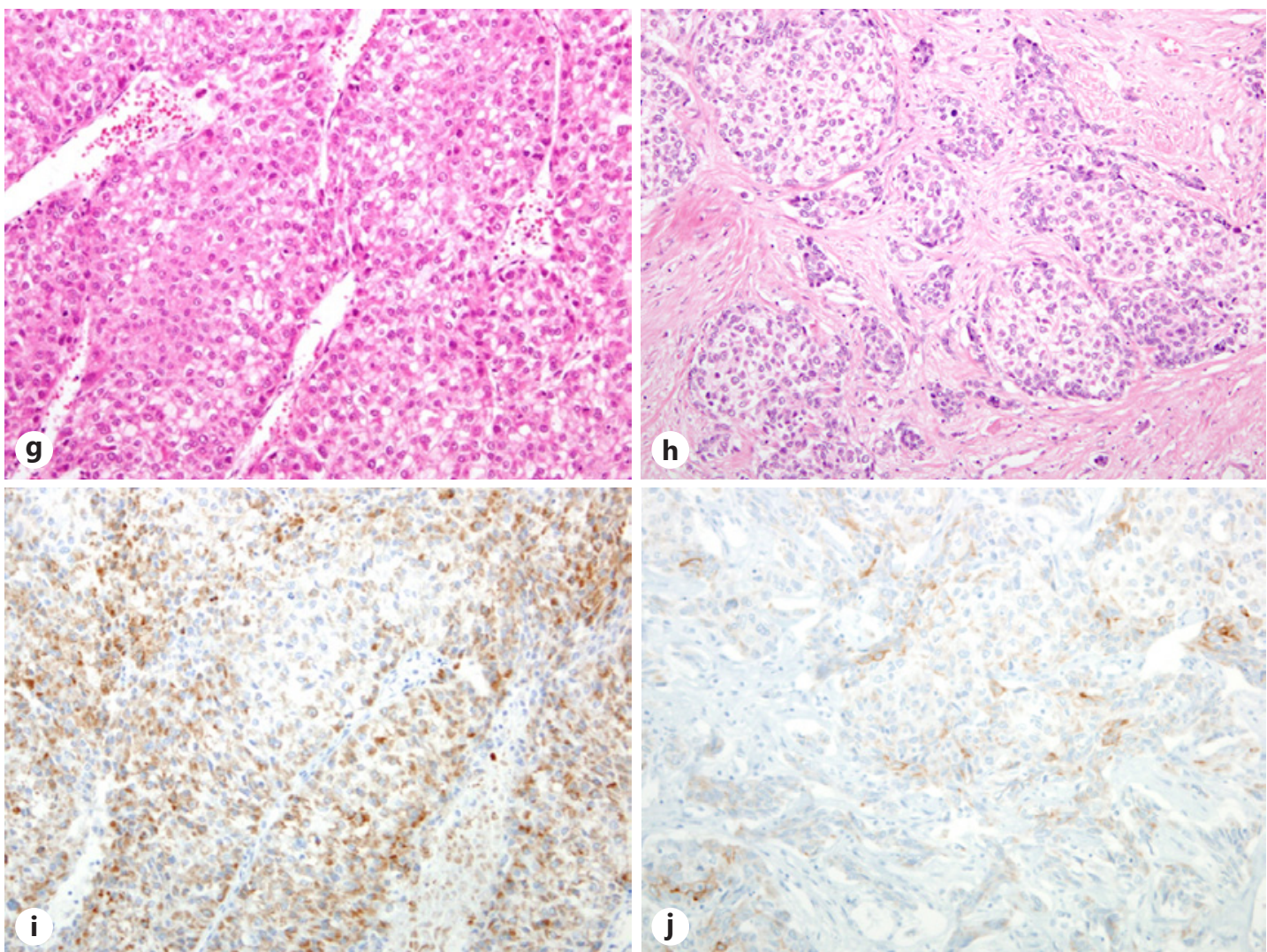

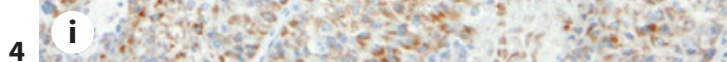

(For legend see next page.)

\section{Karger's}


may be observed in the fibrotic area of the tumor, which may reflect pooling of contrast agent in the extracellular space (Fig. 4d) [88]. The fibrous stroma in K19-positive HCC is also thought to contribute to the targetoid diffusion restriction (Fig. 4e, f) [80, 88]. K19 expression has also been reported in HCCs with macrotrabecular patterns [13], which have often been associated with arterial phase rim-like enhancement [82]. HCCs with macrotrabecular patterns often show a characteristic sinusoid-like microvascular pattern that is related to low microvascular density [82]. As microvascular density of HCC is reflected by the degree of arterial enhancement on MRI, the microvascular characteristics of macrotrabecular HCC may possibly explain the large hypoenhancing areas with rim-like enhancement. In addition, irregular tumor margins and absence of tumor capsules on MRI are characteristics of K19-positive HCCs [79, 80], corresponding to the infiltrative growth patterns seen on histopathology $[7,17]$.

\section{Low Uptake of Gadoxetic Acid in the Hepatobiliary Phase}

Gadoxetic acid is a hepatobiliary contrast agent used for MRI that can demonstrate hepatobiliary uptake function as well as confer dynamic contrast enhancement. After intravenous injection of gadoxetic acid, it is slowly absorbed by normal hepatocytes, increasing the T1 signal intensity of liver parenchyma and reaching the maximum T1 signal intensity between 15 and 20 min after intravenous injection (hepatobiliary phase). The majority of HCCs, including early HCC, show a decreased uptake of gadoxetic acid and lower signal intensity than those of the surrounding non-tumor liver $[89,90]$. However, the hepatobiliary uptake of HCC could be variable, as about $6-25 \%$ of HCCs show predominant signal hyperintensity in the hepatobiliary phase [91]. The uptake of gadoxetic acid is closely associated with the expression of the organic anion transporter OATP1B3 [92, 93]. Although the regulatory mechanism of OATP1B3 is not fully understood, CTNNB1 activating mutation, one of the most common genetic alterations in HCC, has been associated with the upregulation and high expression of OATP1B3 and high hepatobiliary uptake of gadoxetic acid [93]. Interestingly, K19-positive HCCs, in which CTNNB1-activating mutation is rare, have been associated with a decreased expression of OATP1B3 and lower signal intensity in the hepatobiliary phase than K19-negative HCCs [80, 94].

\section{High Uptake of ${ }^{18}$ F-FDG}

Primary liver cancers with cholangiocytic differentiation, including CHCC-CCA and iCCA, demonstrate higher ${ }^{18} \mathrm{~F}$-FDG uptake than HCC $[95,96]$. The ${ }^{18}$ F-FDG uptake of HCC is variable; K19-positive HCC is associated with high ${ }^{18} \mathrm{~F}$-FDG uptake. In addition, high ${ }^{18} \mathrm{~F}$-FDG uptake in HCC has been associated with poor differentiation, microvascular invasion, advanced tumor stage, and a poor outcome after surgical resection or transplantation [97-99]. In an in vitro study, the K19-positive tumor cell subpopulation displayed higher ${ }^{18} \mathrm{~F}$-FDG uptake than the K19-negative subpopulation, and K19 expression was found to increase ${ }^{18}$ F-FDG uptake through TGF- $\beta /$ Smad signaling and the subsequent upregulation of the glucose transporter GLUT1 [83].

Fig. 4. Gadoxetic acid-enhanced MRI of K19-expressing HCC. The lesion shows a low signal intensity in the precontrast T1-weighted image (a), rim-like enhancement in the arterial phase (b), absence of enhancing capsule in the portal phase (c), and low signal intensity and delayed enhancement of central area (white arrows) in the hepatobiliary phase (d). Targetoid restriction on diffusion-weighted image $(\mathbf{e}, b=800)$ and apparent diffusion coefficient image (f). On microscopy, this HCC demonstrates a macrotrabecular pattern (g), focal area of fibrous stroma (h), and K19 expression (i,j) (g, h: hematoxylin-eosin; i, j: immunohistochemical stain for K19, original magnification, ×100). K19, keratin 19; HCC, hepatocellular carcinoma.

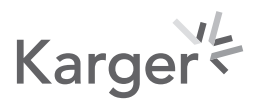


Rhee et al.: Characteristics of Hepatocellular Carcinomas with Keratin 19 Expression

\section{Prognosis and Treatment Resistance of HCC with K19 Expression}

K19-positive HCCs have been associated with poor outcome after curative resection or liver transplantation and treatment resistance to locoregional therapy and systemic chemotherapy.

\section{Hepatic Resection and Liver Transplantation}

K19 expression in HCC has been associated with shorter disease-free survival and overall survival after curative hepatic resection compared to K19-negative HCC [6, 7, 19, 100]. KRT19 has been identified as a poor prognostic marker and included in the "5-gene score" that has been shown to predict poor disease-specific survival in HCC [12]. Several other studies have demonstrated associations between K19 positivity in HCC and more frequent extrahepatic recurrence and shorter extrahepatic recurrence-free survival after hepatic resection $[16,20$, 62].

HCCs with K19 protein expression have also been associated with frequent recurrence and poor survival after transplantation [14, 16]. Moreover, HCCs without K19 protein expression and HCCs not showing K19-related gene expression signatures have demonstrated favorable outcomes after liver transplantation, even for out-of-Milan patients [16, 36]. This suggests that evaluating K19 expression status on biopsy could help identify a group of out-of-Milan HCC patients who could actually be considered candidates for liver transplantation, potentially expanding the criteria for transplantation.

\section{Locoregional Treatment: TACE and RFA}

HCCs with K19 expression are resistant to TACE. On comparing matched pre-TACE biopsies and post-TACE resected tissues from the same HCCs, we found that HCCs with K19 expression more frequently tended to have residual tumors after TACE. In contrast, complete tumor necrosis after TACE was more frequently seen in HCCs that did not express markers associated with stemness (K19 or EpCAM) or hypoxia (carbonic anhydrase-IX [CAIX], which is a hypoxia-inducible factor [HIF]-1 $\alpha$-regulated pH-modifying enzyme), than in HCCs that expressed any of these markers [16]. Residual HCCs after TACE were more frequently positive for stemness-related markers (K19, EpCAM, and CD133) than those without TACE [101, 102], and K19 and CAIX expression were frequently co-localized in the residual HCCs after TACE [103]. Additionally, the expression rate of stemness-related markers increased along with the number of TACE sessions [16]. Hypoxia has been proposed to play an important role in the growth of cancer stem cells through activation of the HIF- $1 \alpha / \mathrm{HIF}-2 \alpha$ pathway in in vitro studies; therefore, it is possible that the cancer stem cell population (including K19-positive HCC cells) increases when exposed to a hypoxic microenvironment by TACE [104]. Under hypoxic conditions, HIF- $1 \alpha$ and TGF- $\beta$ interact with each other, resulting in increased expression of both HIF- $1 \alpha$ and TGF- $\beta$, and enhanced TGF- $\beta$ has been demonstrated to upregulate the expression of $\alpha$-smooth muscle actin [105]. The tumor microenvironment was also found to be altered after TACE: the expression of hypoxia (CAIX and VEGF) and stromal (fibroblast activation protein and $\alpha$-smooth muscle actin) markers increased after TACE [63]. These changes in the microenvironment may partly account for the resistance of K19-positive HCCs to TACE (Fig. 5).

There are limited data regarding the effect of RFA therapy on K19-positive HCCs. A significantly shorter recurrence-free survival after RFA has been reported in K19-positive HCCs than in K19-negative HCCs [9]. The local tumor recurrence after RFA is considered to be associated with cancer stem cell activation, as suboptimal ablation of HCC was shown to induce an aggressive phenotype in in vitro and animal studies, including K19 expression and EMT-like features $[106,107]$.

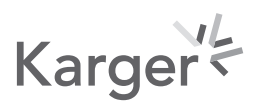




\begin{tabular}{ll|l} 
Liver Cancer & \multicolumn{2}{l}{ Liver Cancer 2020;9:663-681 } \\
\cline { 2 - 3 } DOI: 10.1159/000510522 & $\begin{array}{l}\text { @ 2020 The Author(s). Published by S. Karger AG, Basel } \\
\text { www.karger.com/lic }\end{array}$ \\
\cline { 2 - 2 }
\end{tabular}

Rhee et al.: Characteristics of Hepatocellular Carcinomas with Keratin 19 Expression

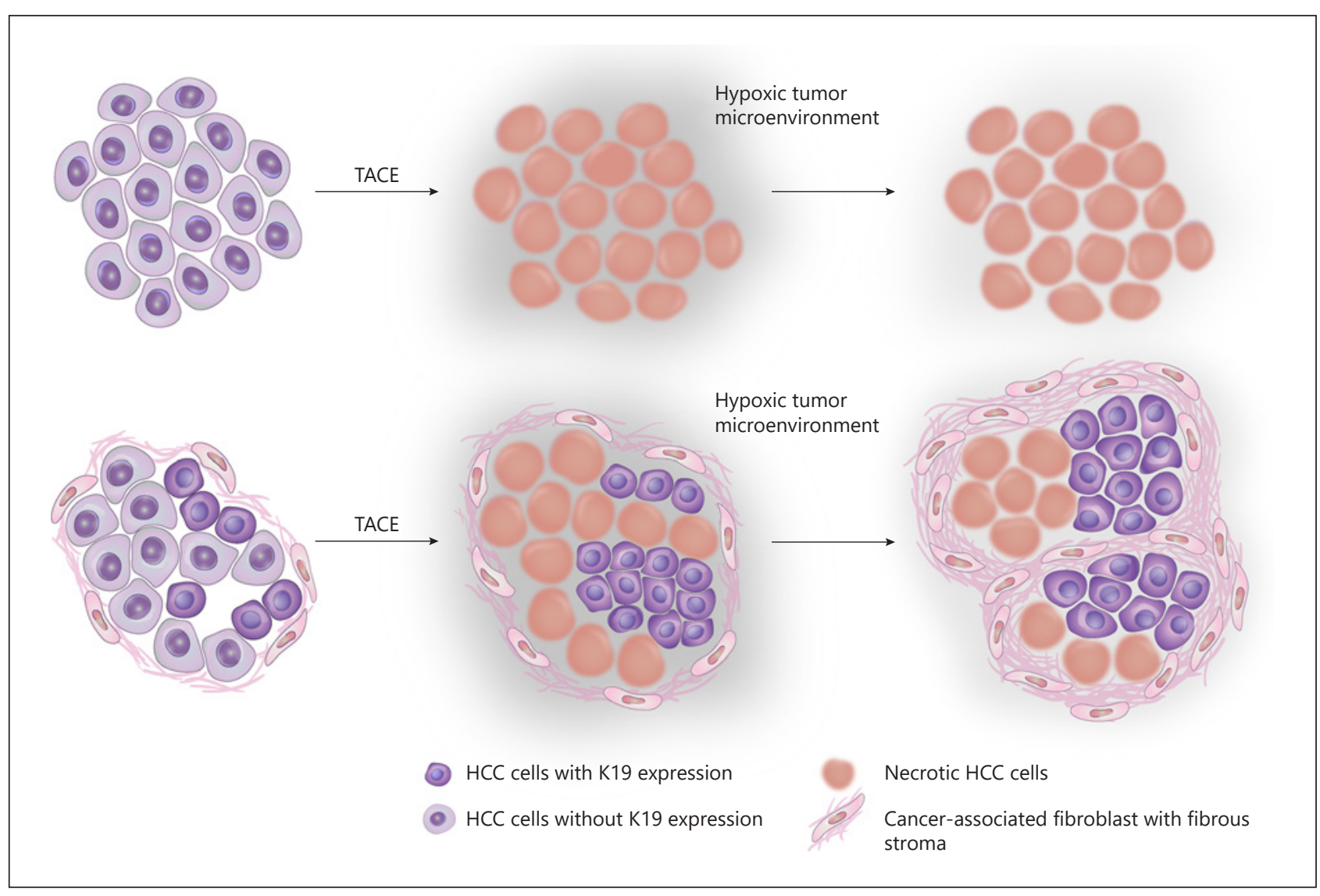

Fig. 5. Model of treatment resistance to TACE in K19-expressing HCC. HCC cells without K19 expression are more susceptible to TACE with a higher chance of near total necrosis than those with K19 expression. In contrast, HCC cells with K19 expression may be resistant to a hypoxic tumor microenvironment induced by TACE and have higher chance of incomplete necrosis. In addition, they can proliferate with altered tumor stroma after TACE. TACE, transarterial chemoembolization; K19, keratin 19; HCC, hepatocellular carcinoma.

Systemic Chemotherapy and Immunotherapy

HCCs with stemness-related markers have been considered to be resistant to systemic chemotherapy. K19-positive HCCs have shown resistance to chemotherapeutic agents, such as 5 -FU, doxorubicin, and sorafenib, in in vitro studies $[8,14]$. Sorafenib resistance was associated with the gene signature of K19-positive HCC [108], and also with EMT and a hypoxic microenvironment, which are characteristics of K19-positive HCCs [109]. MET activation has been observed in K19-positive HCCs; therefore, MET inhibitors could be potential candidates for systemic therapy of these tumors [50]. In a drug screening study using a large panel of liver cancer cell lines, K19 expression was associated with high sensitivity to dasatinib, an SRC inhibitor [110]. Further study is needed to investigate how K19-positive HCCs respond to recently approved chemotherapeutic agents (e.g., lenvatinib, regorafenib, ramucirumab, and cabozantinib).

Immune checkpoint inhibitor therapy for HCC has received increasing attention over the past several years, and so far, nivolumab and pembrolizumab have gained approval as 2nd-line treatment for advanced HCCs after the CheckMate-040 and KEYNOTE-224 trials, respectively [111, 112]. It remains to be seen if K19-positive HCCs respond to the currently approved immune checkpoint inhibitors. PD-L1 expression in relation to K19 status has not 
been well characterized, although PD-L1 expression has been identified in from $15 \%$ to as many as $83 \%$ of HCCs; this variability is most likely due to the inter-assay variability depending on the different clones available and the differing interpretation methods [113, 114]. An association between high PD-L1 expression and K19 positivity has been reported in one study [115]; however, further validation would be required. By integrating the immune microenvironmental status with the K19 expression status, we may find biomarkers for HCC that are clinically relevant from the immunotherapeutic point of view.

\section{Conclusion and Future Perspective}

Various clinicopathological studies over the past decades have suggested a role for K19 expression as a prognostic biomarker for HCC, and this notion has been supported by an increasing amount of large-scale molecular data generated in the recent years. From a clinical perspective, K19-positive HCCs comprise a prognostically important subset of HCC, as they have been repeatedly associated with decreased patient survival, earlier recurrence after both surgical and nonsurgical treatment, increased resistance to chemotherapy, TACE and RFA, and aggressive clinicopathological features, such as frequent vascular invasion. Therefore, the immunohistochemical identification of K19 expression in HCC tissues obtained by biopsy, resection, or transplantation could potentially provide useful information for predicting prognosis and therapeutic response for HCC patients.

However, despite the increasing interest in K19 as a predictive biomarker, there are hurdles to be overcome before K19 assessment can be formally integrated into clinical practice. As liver biopsy is not mandatory for a diagnosis of HCC according to the current guidelines [67-69], the role of $\mathrm{K} 19$ immunohistochemistry is at present limited. The indications for liver biopsy could be refined; for example, K19 positivity predicted by noninvasive diagnostic modalities could be an indication for biopsy in order to confirm K19-positive HCCs by immunohistochemistry. Indeed, K19-positive HCCs frequently show atypical imaging findings, including arterial phase rim-like enhancement, low arterial enhancement, and absence of washout; therefore, identifying the presence of such imaging features in hepatic lesions could call for a liver biopsy. In addition, serum markers, such as alpha-fetoprotein, CYFRA21-1, and circulating tumor cells, could potentially serve as useful surrogates of K19-positive HCCs. Such noninvasive diagnostic surrogates of K19 expression should be further explored and validated in large-scale prospective studies.

From the therapeutic point of view, as K19-positive HCCs are highly invasive tumors with frequent extrahepatic dissemination, systemic chemotherapy may be indicated to improve the prognosis of patients with these tumors. However, the chemoresistant nature of K19-positive HCCs may pose obstacles in the treatment of these tumors. Targeting specific molecular pathways that are activated in K19-positive HCCs, such as MET or SRC, could potentially open new therapeutic options for these tumors, and K19 could serve as useful predictors of treatment response to targeted therapy. In addition, examining the immune microenvironment of HCC in the context of K19 status could also provide important information for identifying a subgroup of HCC patients for whom immune checkpoint therapy could be beneficial. Taken together, the recent accumulation of molecular data has provided further insight into the genetic, epigenetic, and immunological characteristics of K19-positive HCCs, and targeted therapy for this aggressive subset of HCC is highly anticipated.

\section{Karger ${ }^{\prime \prime}=$}




\begin{tabular}{l|l}
\hline Liver Cancer 2020;9:663-681 \\
\hline DOI: 10.1159/000510522 & $\begin{array}{l}\text { @ 2020 The Author(s). Published by S. Karger AG, Basel } \\
\text { www.karger.com/lic }\end{array}$ \\
\hline
\end{tabular}

Rhee et al.: Characteristics of Hepatocellular Carcinomas with Keratin 19 Expression

\section{Acknowledgement}

The authors would like to thank Dr. Neil D. Theise for his insightful suggestions and careful reading of the manuscript.

\section{Conflict of Interest Statement}

The authors have no conflicts of interest to declare.

\section{Funding Sources}

This research was supported by the basic science research program through the National Research Foundation of Korea (NRF) funded by the Ministry of Science, ICT and future planning (NRF2020R1A2B5B01001646, YNP), the Bio \& Medical Technology Development Program of the National Research Foundation (NRF) and funded by the Korean government (MSIP \& MOHW) (NRF2017M3A9B6061512, Y.N.P.), the NRF grant funded by the Korean government (MSIT) (NRF2019R1A2C2010056, HK), and the NRF grant funded by the Korean government (MSIT) (NRF2020R1C1C1003887, HR).

\section{Author Contributions}

Hyungjin Rhee and Haeryoung Kim: funding acquisition, investigation, and writing - original draft, review, and editing. Young Nyun Park: conceptualization, funding acquisition, investigation, supervision, and writing - original draft, review, and editing.

\section{References}

1 Bray F, Ferlay J, Soerjomataram I, Siegel RL, Torre LA, Jemal A. Global cancer statistics 2018: GLOBOCAN estimates of incidence and mortality worldwide for 36 cancers in 185 countries. CA Cancer J Clin. 2018;68(6): 394-424.

2 Torbenson MS, Ng IOL, Park YN, Roncalli M, Sakamoto M. Hepatocellular carcinoma. In: WHO Classification of Tumours Editorial Board, editor. Digestive system tumours. Lyon: International Agency for Research on Cancer; 2019. p. 229-39.

3 Bragulla HH, Homberger DG. Structure and functions of keratin proteins in simple, stratified, keratinized and cornified epithelia. J Anat. 2009;214(4):516-59.

4 Roskams T. Liver stem cells and their implication in hepatocellular and cholangiocarcinoma. Oncogene. 2006; 25(27):3818-22.

5 Durnez A, Verslype C, Nevens F, Fevery J, Aerts R, Pirenne J, et al. The clinicopathological and prognostic relevance of cytokeratin 7 and 19 expression in hepatocellular carcinoma. A possible progenitor cell origin. Histopathology. 2006;49(2):138-51.

6 Uenishi T, Kubo S, Yamamoto T, Shuto T, Ogawa M, Tanaka H, et al. Cytokeratin 19 expression in hepatocellular carcinoma predicts early postoperative recurrence. Cancer Sci. 2003;94(10):851-7.

7 Kim H, Choi GH, Na DC, Ahn EY, Kim GI, Lee JE, et al. Human hepatocellular carcinomas with “Stemness"-related marker expression: keratin 19 expression and a poor prognosis. Hepatology. 2011;54(5):1707-17.

8 Govaere 0, Komuta M, Berkers J, Spee B, Janssen C, de Luca F, et al. Keratin 19: a key role player in the invasion of human hepatocellular carcinomas. Gut. 2014;63(4):674-85.

9 Tsuchiya K, Komuta M, Yasui Y, Tamaki N, Hosokawa T, Ueda K, et al. Expression of keratin 19 is related to high recurrence of hepatocellular carcinoma after radiofrequency ablation. Oncology. 2011;80(3-4):278-88.

10 Boyault S, Rickman DS, de Reyniès A, Balabaud C, Rebouissou S, Jeannot E. Transcriptome classification of HCC is related to gene alterations and to new therapeutic targets. Hepatology. 2007;45(1):42-52.

11 Hoshida Y, Nijman SM, Kobayashi M, Chan JA, Brunet JP, Chiang DY, et al. Integrative transcriptome analysis reveals common molecular subclasses of human hepatocellular carcinoma. Cancer Res. 2009;69(18):738592.

12 Nault JC, De Reyniès A, Villanueva A, Calderaro J, Rebouissou S, Couchy G, et al. A hepatocellular carcinoma 5-gene score associated with survival of patients after liver resection. Gastroenterology. 2013;145(1):176-87.

13 Calderaro J, Couchy G, Imbeaud S, Amaddeo G, Letouzé E, Blanc JF, et al. Histological subtypes of hepatocellular carcinoma are related to gene mutations and molecular tumour classification. J Hepatol. 2017;67(4):727-38. 
14 Kawai T, Yasuchika K, Ishii T, Katayama H, Yoshitoshi EY, Ogiso S, et al. Keratin 19, a cancer stem cell marker in human hepatocellular carcinoma. Clin Cancer Res. 2015;21(13):3081-91.

15 Theise N, Curado M, Franceschi S, Hytiroglou P, Kudo M, Park Y, et al. Hepatocellular carcinoma. In: Bosman F, Carneiro F, Hruban R, Theise N, editors. WHO classification of tumours of the digestive system. Lyon: IARC; 2010. p. 205-16.

16 Rhee H, Nahm JH, Kim H, Choi GH, Yoo JE, Lee HS, et al. Poor outcome of hepatocellular carcinoma with stemness marker under hypoxia: resistance to transarterial chemoembolization. Mod Pathol. 2016;29(9): 1038-49.

17 Lee Y, Park H, Lee H, Cho JY, Yoon Y-S, Choi Y-R. The clinicopathological and prognostic significance of the gross classification of hepatocellular carcinoma. J Pathol Transl Med. 2018;52(2):85-92.

18 Rhee H, Chung T, Yoo JE, Nahm JH, Woo HY, Choi GH, et al. Gross type of hepatocellular carcinoma reflects the tumor hypoxia, fibrosis, and stemness-related marker expression. Hepatol Int. 2020;14(2):239-48.

19 Zhuang PY, Zhang JB, Zhu XD, Zhang W, Wu WZ, Tan YS, et al. Two pathologic types of hepatocellular carcinoma with lymph node metastasis with distinct prognosis on the basis of CK19 expression in tumor. Cancer. 2008; 112(12):2740-8.

20 Takano M, Shimada K, Fujii T, Morita K, Takeda M, Nakajima Y, et al. Keratin 19 as a key molecule in progression of human hepatocellular carcinomas through invasion and angiogenesis. BMC cancer. 2016;16(1):903.

21 Kurogi M, Nakashima O, Miyaaki H, Fujimoto M, Kojiro M. Clinicopathological study of scirrhous hepatocellular carcinoma. J Gastroenterol Hepatol. 2006;21(9):1470-7.

22 Seok JY, Na DC, Woo HG, Roncalli M, Kwon SM, Yoo JE, et al. A fibrous stromal component in hepatocellular carcinoma reveals a cholangiocarcinoma-like gene expression trait and epithelial-mesenchymal transition. Hepatology. 2012;55(6):1776-86.

23 Kim YJ, Rhee H, Yoo JE, Alves VAF, Kim GJ, Kim HM, et al. Tumour epithelial and stromal characteristics of hepatocellular carcinomas with abundant fibrous stroma: fibrolamellar versus scirrhous hepatocellular carcinoma. Histopathology. 2017;71(2):217-26.

24 Sempoux C, Kakar S, Kondo F, Schirmacher P. Combined hepatocellular-cholangiocarcinoma and undifferentiated primary liver carcinoma. In: WHO Classification of Tumours Editorial Board, editor. Digestive system tumours. Lyon: International Agency for Research on Cancer; 2019. p. 260-2.

25 Kim H, Park C, Han KH, Choi J, Kim YB, Kim JK, et al. Primary liver carcinoma of intermediate (hepatocytecholangiocyte) phenotype. J Hepatol. 2004;40(2):298-304.

26 Andersen JB, Loi R, Perra A, Factor VM, Ledda-Columbano GM, Columbano A, et al. Progenitor-derived hepatocellular carcinoma model in the rat. Hepatology. 2010;51(4):1401-9.

27 Villanueva A, Hoshida Y, Battiston C, Tovar V, Sia D, Alsinet C, et al. Combining clinical, pathology, and gene expression data to predict recurrence of hepatocellular carcinoma. Gastroenterology. 2011;140(5):1501-e2.

28 Cairo S, Armengol C, De Reyniès A, Wei Y, Thomas E, Renard CA, et al. Hepatic stem-like phenotype and interplay of Wnt/beta-catenin and Myc signaling in aggressive childhood liver cancer. Cancer cell. 2008;14(6): 471-84.

29 Woo HG, Lee JH, Yoon JH, Kim CY, Lee HS, Jang JJ, et al. Identification of a cholangiocarcinoma-like gene expression trait in hepatocellular carcinoma. Cancer Res. 2010;70(8):3034-41.

30 Yamashita T, Forgues M, Wang W, Kim JW, Ye Q, Jia H, et al. EpCAM and alpha-fetoprotein expression defines novel prognostic subtypes of hepatocellular carcinoma. Cancer Res. 2008;68(5):1451-61.

31 Lee JS, Chu IS, Heo J, Calvisi DF, Sun Z, Roskams T, et al. Classification and prediction of survival in hepatocellular carcinoma by gene expression profiling. Hepatology. 2004;40(3):667-76.

32 Chiang DY, Villanueva A, Hoshida Y, Peix J, Newell P, Minguez B, et al. Focal gains of VEGFA and molecular classification of hepatocellular carcinoma. Cancer Res. 2008;68(16):6779-88.

33 Coulouarn C, Factor VM, Thorgeirsson SS. Transforming growth factor-beta gene expression signature in mouse hepatocytes predicts clinical outcome in human cancer. Hepatology. 2008;47(6):2059-67.

34 Kaposi-Novak P, Lee JS, Gòmez-Quiroz L, Coulouarn C, Factor VM, Thorgeirsson SS. Met-regulated expression signature defines a subset of human hepatocellular carcinomas with poor prognosis and aggressive phenotype. J Clin Invest. 2006;116(6):1582-95.

35 Minguez B, Hoshida Y, Villanueva A, Toffanin S, Cabellos L, Thung S, et al. Gene-expression signature of vascular invasion in hepatocellular carcinoma. J Hepatol. 2011;55(6):1325-31.

36 Miltiadous O, Sia D, Hoshida Y, Fiel MI, Harrington AN, Thung SN, et al. Progenitor cell markers predict outcome of patients with hepatocellular carcinoma beyond Milan criteria undergoing liver transplantation. J Hepatol. 2015;63(6):1368-77.

37 Shimada S, Mogushi K, Akiyama Y, Furuyama T, Watanabe S, Ogura T, et al. Comprehensive molecular and immunological characterization of hepatocellular carcinoma. EBioMedicine. 2019;40:457-70.

38 Cancer Genome Atlas Research Network. Electronic address wbe, cancer genome atlas research N: comprehensive and integrative genomic characterization of hepatocellular carcinoma. Cell. 2017;169:1327-41 e1323.

39 Sia D, Jiao Y, Martinez-Quetglas I, Kuchuk O, Villacorta-Martin C, Castro de Moura M, et al. Identification of an immune-specific class of hepatocellular carcinoma, based on molecular features. Gastroenterology. 2017; 153(3):812-26. 


\begin{tabular}{|c|c|}
\hline Liver Cancer 2020;9:663-681 & \\
\hline DOI: 10.1159/000510522 & $\begin{array}{l}\text { (c) } 2020 \text { The Author(s). Published by S. Karger AG, Basel } \\
\text { www.karger.com/lic }\end{array}$ \\
\hline
\end{tabular}

Rhee et al.: Characteristics of Hepatocellular Carcinomas with Keratin 19 Expression

40 Kurebayashi Y, Ojima H, Tsujikawa H, Kubota N, Maehara J, Abe Y, et al. Landscape of immune microenvironment in hepatocellular carcinoma and its additional impact on histological and molecular classification. Hepatology. 2018;68(3):1025-41.

41 Fang JH, Zhou HC, Zhang C, Shang LR, Zhang L, Xu J, et al. A novel vascular pattern promotes metastasis of hepatocellular carcinoma in an epithelial-mesenchymal transition-independent manner. Hepatology. 2015; 62(2): 452-65.

42 Renne SL, Woo HY, Allegra S, Rudini N, Yano H, Donadon M. Vessels encapsulating tumor clusters (VETC) is a powerful predictor of aggressive hepatocellular carcinoma. Hepatology. 2020;71(1):183-95.

43 Kim H, Yoo JE, Cho JY, Oh BK, Yoon YS, Han HS, et al. Telomere length, TERT and shelterin complex proteins in hepatocellular carcinomas expressing "stemness"-related markers. J Hepatol. 2013;59(4):746-52.

44 Oh BK, Kim H, Park YN, Yoo JE, Choi J, Kim KS, et al. High telomerase activity and long telomeres in advanced hepatocellular carcinomas with poor prognosis. Lab Invest. 2008;88(2):144-52.

45 Mu X, Español-Suñer R, Mederacke I, Affò S, Manco R, Sempoux C, et al. Hepatocellular carcinoma originates from hepatocytes and not from the progenitor/biliary compartment. J Clin Invest. 2015;125(10):3891-903.

46 Shin S, Wangensteen KJ, Teta-Bissett M, Wang YJ, Mosleh-Shirazi E, Buza EL, et al. Genetic lineage tracing analysis of the cell of origin of hepatotoxin-induced liver tumors in mice. Hepatology. 2016;64(4):1163-77.

47 Kowalik MA, Sulas P, Ledda-Columbano GM, Giordano S, Columbano A, Perra A. Cytokeratin-19 positivity is acquired along cancer progression and does not predict cell origin in rat hepatocarcinogenesis. Oncotarget. 2015;6(36):38749-63.

48 Yoo JE, Kim YJ, Rhee H, Kim H, Ahn EY, Choi JS, et al. Progressive enrichment of stemness features and tumor stromal alterations in multistep hepatocarcinogenesis. PLoS One. 2017;12(1):e0170465.

49 Blumenberg M. Transcriptional regulation of keratin gene expression. In: Paramio J, editor. Intermediate filaments. New York, NY: Springer; 2006. p. 93-109.

50 Rhee H, Kim HY, Choi JH, Woo HG, Yoo JE, Nahm JH, et al. Keratin 19 expression in hepatocellular carcinoma is regulated by fibroblast-derived HGF via a MET-ERK1/2-AP1 and SP1 axis. Cancer Res. 2018;78(7):1619-31.

51 Boccaccio C, Comoglio PM. Invasive growth: a MET-driven genetic programme for cancer and stem cells. Nat Rev Cancer. 2006;6(8):637-45.

52 Lau EY, Lo J, Cheng BY, Ma MK, Lee JM, Ng JK, et al. Cancer-associated fibroblasts regulate tumor-initiating cell plasticity in hepatocellular carcinoma through c-Met/FRA1/HEY1 signaling. Cell Rep. 2016;15(6):1175-89.

53 Yoneda N, Sato Y, Kitao A, Ikeda H, Sawada-Kitamura S, Miyakoshi M, et al. Epidermal growth factor induces cytokeratin 19 expression accompanied by increased growth abilities in human hepatocellular carcinoma. Lab Invest. 2010;91(2):262-72.

54 Lorenzini S, Bird TG, Boulter L, Bellamy C, Samuel K, Aucott R, et al. Characterisation of a stereotypical cellular and extracellular adult liver progenitor cell niche in rodents and diseased human liver. Gut. 2010;59(5):64554.

55 Neubauer K, Krüger M, Quondamatteo F, Knittel T, Saile B, Ramadori G. Transforming growth factor-beta1 stimulates the synthesis of basement membrane proteins laminin, collagen type IV and entactin in rat liver sinusoidal endothelial cells. J Hepatol. 1999;31(4):692-702.

56 Maher JJ, Friedman SL, Roll FJ, Bissell DM. Immunolocalization of laminin in normal rat liver and biosynthesis of laminin by hepatic lipocytes in primary culture. Gastroenterology. 1988;94(4):1053-62.

57 Petz M, Them NC, Huber H, Mikulits W. PDGF enhances IRES-mediated translation of Laminin B1 by cytoplasmic accumulation of La during epithelial to mesenchymal transition. Nucleic Acids Res. 2012;40(19): 9738-49.

58 Govaere O, Petz M, Wouters J, Vandewynckel YP, Scott EJ, Topal B, et al. The PDGFR $\alpha$-laminin B1-keratin 19 cascade drives tumor progression at the invasive front of human hepatocellular carcinoma. Oncogene. 2017; 36(47):6605-16.

59 Govaere 0, Wouters J, Petz M, Vandewynckel YP, Van den Eynde K, Van den Broeck A, et al. Laminin-332 sustains chemoresistance and quiescence as part of the human hepatic cancer stem cell niche. J Hepatol. 2016; 64(3):609-17.

60 Giannelli G, Fransvea E, Bergamini C, Marinosci F, Antonaci S. Laminin-5 chains are expressed differentially in metastatic and nonmetastatic hepatocellular carcinoma. Clin Cancer Res. 2003;9(10 Pt 1):3684-91.

61 Marquardt JU, Raggi C, Andersen JB, Seo D, Avital I, Geller D, et al. Human hepatic cancer stem cells are characterized by common stemness traits and diverse oncogenic pathways. Hepatology. 2011;54(3):1031-42.

62 Yokomichi N, Nishida N, Umeda Y, Taniguchi F, Yasui K, Toshima T, et al. Heterogeneity of epigenetic and epithelial mesenchymal transition marks in hepatocellular carcinoma with keratin 19 proficiency. Liver cancer. 2019;8(4):239-54.

63 Nahm JH, Rhee H, Kim H, Yoo JE, San Lee J, Jeon Y, et al. Increased expression of stemness markers and altered tumor stroma in hepatocellular carcinoma under TACE-induced hypoxia: a biopsy and resection matched study. Oncotarget. 2017;8(59):99359-71.

64 Bottger V, Stasiak PC, Harrison DL, Mellerick DM, Lane EB. Epitope mapping of monoclonal antibodies to keratin 19 using keratin fragments, synthetic peptides and phage peptide libraries. Eur J Biochem. 1995; 231(2):475-85.

65 La Rosa S, Rigoli E, Uccella S, Novario R, Capella C. Prognostic and biological significance of cytokeratin 19 in pancreatic endocrine tumours. Histopathology. 2007;50(5):597-606. 
Dalal P, Shousha S. Keratin 19 in paraffin sections of medullary carcinoma and other benign and malignant breast lesions. Mod Pathol. 1995;8(4):413-6.

67 Marrero JA, Kulik LM, Sirlin CB, Zhu AX, Finn RS, Abecassis MM, et al. Diagnosis, staging, and management of hepatocellular carcinoma: 2018 practice guidance by the American Association for the study of liver diseases. Hepatology. 2018;68(2):723-50.

68 European association for the study of the liver: EASL clinical practice guidelines: management of hepatocellular carcinoma. J Hepatol. 2018;69(1):182-236.

69 Omata M, Cheng AL, Kokudo N, Kudo M, Lee JM, Jia J, et al. Asia-Pacific clinical practice guidelines on the management of hepatocellular carcinoma: a 2017 update. Hepatol Int. 2017;11(4):317-70.

70 Stigbrand T, Andres C, Bellanger L, Bishr Omary M, Bodenmuller H, Bonfrer H, et al. Epitope specificity of 30 monoclonal antibodies against cytokeratin antigens: the ISOBM TD5-1 workshop. Tumour Biol. 1998;19:13252.

71 Pujol L, Molinier O, Ebert W, Daures JP, Barlesi F, Buccheri G, et al. CYFRA 21-1 is a prognostic determinant in non-small-cell lung cancer: results of a meta-analysis in 2063 patients. Br J Cancer. 2004;90(11):2097-105.

72 Guowei H, Yuan L, Ma L, Zhongyang L, Zhixing S, Lin L, et al. The diagnostic efficacy of CYFRA21-1 on intrahepatic cholangiocarcinoma: a meta-analysis. Clin Res Hepatol Gastroenterol. 2019;43(3):266-72.

73 Uenishi T, Kubo S, Hirohashi K, Tanaka H, Shuto T, Yamamoto T, et al. Cytokeratin-19 fragments in serum (CYFRA 21-1) as a marker in primary liver cancer. Br J Cancer. 2003;88(12):1894-9.

74 Li Y, Tang ZY, Tian B, Ye SL, Qin LX, Xue Q, et al. Serum CYFRA 21-1 level reflects hepatocellular carcinoma metastasis: study in nude mice model and clinical patients. J Cancer Res Clin Oncol. 2006;132(8):515-20.

75 Nagai T, Murota M, Nishioka M, Fujita J, Ohtsuki Y, Dohmoto K, et al. Elevation of cytokeratin 19 fragment in serum in patients with hepatoma: its clinical significance. Eur J Gastroenterol Hepatol. 2001;13(2):157-61.

76 Kawai T, Yasuchika K, Ishii T, Katayama H, Yoshitoshi EY, Ogiso S, et al. Identification of keratin 19-positive cancer stem cells associating human hepatocellular carcinoma using CYFRA 21-1. Cancer Med. 2017;6(11): 2531-40.

77 Uenishi T, Yamazaki O, Yamamoto T, Hirohashi K, Tanaka H, Tanaka S, et al. Clinical significance of serum cytokeratin-19 fragment (CYFRA 21-1) in hepatocellular carcinoma. J Hepatobiliary Pancreat Surg. 2006;13:23944.

78 Choi GH, Kim GI, Yoo JE, Na DC, Han DH, Roh YH, et al. Increased expression of circulating cancer stem cell markers during the perioperative period predicts early recurrence after curative resection of hepatocellular carcinoma. Ann Surg Oncol. 2015;22(Suppl 3):S1444-52.

79 Jeong HT, Kim MJ, Kim YE, Park YN, Choi GH, Choi JS. MRI features of hepatocellular carcinoma expressing progenitor cell markers. Liver Int. 2012;32(3):430-40.

80 Choi SY, Kim SH, Park CK, Min JH, Lee JE, Choi YH, et al. Imaging features of gadoxetic acid-enhanced and diffusion-weighted mr imaging for identifying cytokeratin 19-positive hepatocellular carcinoma: a retrospective observational study. Radiology. 2018;286(3):897-908.

81 Choi JY, Kim MJ, Park YN, Lee JM, Yoo SK, Rha SY, et al. Gadoxetate disodium-enhanced hepatobiliary phase MRI of hepatocellular carcinoma: correlation with histological characteristics. AJR Am J Roentgenol. 2011; 197(2):399-405.

82 Rhee H, An C, Kim HY, Yoo JE, Park YN, Kim MJ. Hepatocellular carcinoma with irregular rim-like arterial phase hyperenhancement: more aggressive pathologic features. Liver cancer. 2019;8(1):24-40.

83 Kawai T, Yasuchika K, Seo S, Higashi T, Ishii T, Miyauchi Y. Identification of Keratin 19-positive cancer stem cells associating human hepatocellular carcinoma using $18 \mathrm{~F}$-fluorodeoxyglucose positron emission tomographyidentification of Keratin 19-positive cancer stem cells associating human hepatocellular carcinoma using 18 F-fluorodeoxyglucose positron emission tomography. Clin Cancer Res. 2017;23(6):1450-60.

84 Chung GE, Lee JH, Yoon JH, Myung SJ, Lee K, Jang JJ, et al. Prognostic implications of tumor vascularity and its relationship to cytokeratin 19 expression in patients with hepatocellular carcinoma. Abdom Imaging. 2012; $37(3): 439-46$.

85 Heimbach JK, Kulik LM, Finn RS, Sirlin CB, Abecassis MM, Roberts LR, et al. AASLD guidelines for the treatment of hepatocellular carcinoma. Hepatology. 2018;67(1):358-80.

86 Liver EAftSot. EASL clinical practice guidelines: management of hepatocellular carcinoma. J Hepatol. 2018; 69(1):182-236.

87 Kim SH, Lim HK, Lee WJ, Choi D, Park CK. Scirrhous hepatocellular carcinoma: comparison with usual hepatocellular carcinoma based on CT-pathologic features and long-term results after curative resection. Eur J Radiol. 2009;69(1):123-30.

88 Park MJ, Kim YK, Park HJ, Hwang J, Lee WJ. Scirrhous hepatocellular carcinoma on gadoxetic acid-enhanced magnetic resonance imaging and diffusion-weighted imaging: emphasis on the differentiation of intrahepatic cholangiocarcinoma. J Comput Assist Tomogr. 2013;37(6):872-81.

89 Sano K, Ichikawa T, Motosugi U, Sou H, Muhi AM, Matsuda M, et al. Imaging study of early hepatocellular carcinoma: usefulness of gadoxetic acid-enhanced MR imaging. Radiology. 2011;261(3):834-44.

90 Rhee H, Kim MJ, Park MS, Kim KA. Differentiation of early hepatocellular carcinoma from benign hepatocellular nodules on gadoxetic acid-enhanced MRI. Br J Radiol. 2012;85(1018):e837-44.

91 Kim JY, Kim MJ, Kim KA, Jeong HT, Park YN. Hyperintense HCC on hepatobiliary phase images of gadoxetic acid-enhanced MRI: correlation with clinical and pathological features. Eur J Radiol. 2012;81(12):3877-82. 


\begin{tabular}{|c|c|}
\hline \multicolumn{2}{|c|}{ Liver Cancer 2020;9:663-681 } \\
\hline DOI: 10.1159/000510522 & $\begin{array}{l}\text { () } 2020 \text { The Author(s). Published by S. Karger AG, Basel } \\
\text { www.karger.com/lic }\end{array}$ \\
\hline
\end{tabular}

Rhee et al.: Characteristics of Hepatocellular Carcinomas with Keratin 19 Expression

92 Kitao A, Matsui O, Yoneda N, Kozaka K, Shinmura R, Koda W, et al. The uptake transporter OATP8 expression decreases during multistep hepatocarcinogenesis: correlation with gadoxetic acid enhanced MR imaging. Eur Radiol. 2011;21(10):2056-66.

93 Ueno A, Masugi Y, Yamazaki K, Komuta M, Effendi K, Tanami Y, et al. OATP1B3 expression is strongly associated with Wnt/ $\beta$-catenin signalling and represents the transporter of gadoxetic acid in hepatocellular carcinoma. J Hepatol. 2014;61(5):1080-7.

94 Yamashita T, Kitao A, Matsui O, Hayashi T, Nio K, Kondo M, et al. Gd-EOB-DTPA-enhanced magnetic resonance imaging and alpha-fetoprotein predict prognosis of early-stage hepatocellular carcinoma. Hepatology. 2014; 60(5):1674-85.

95 Ijichi H, Shirabe K, Taketomi A, Yoshizumi T, Ikegami T, Mano Y, et al. Clinical usefulness of (18) F-fluorodeoxyglucose positron emission tomography/computed tomography for patients with primary liver cancer with special reference to rare histological types, hepatocellular carcinoma with sarcomatous change and combined hepatocellular and cholangiocarcinoma. Hepatol Res. 2013;43(5):481-7.

96 Song JY, Lee YN, Kim YS, Kim SG, Jin SJ, Park JM, et al. Predictability of preoperative 18F-FDG PET for histopathological differentiation and early recurrence of primary malignant intrahepatic tumors. Nucl Med Commun. 2015;36(4):319-27.

97 Seo S, Hatano E, Higashi T, Hara T, Tada M, Tamaki N, et al. Fluorine-18 fluorodeoxyglucose positron emission tomography predicts tumor differentiation, P-glycoprotein expression, and outcome after resection in hepatocellular carcinoma. Clin Cancer Res. 2007;13(2 Pt 1):427-33.

98 Lim C, Salloum C, Chalaye J, Lahat E, Costentin CE, Osseis M, et al. 18F-FDG PET/CT predicts microvascular invasion and early recurrence after liver resection for hepatocellular carcinoma: a prospective observational study. HPB. 2019;21(6):739-47.

99 Yoh T, Seo S, Ogiso S, Kawai T, Okuda Y, Ishii T, et al. Proposal of a new preoperative prognostic model for solitary hepatocellular carcinoma incorporating (18)F-FDG-PET imaging with the ALBI grade. Ann Surg Oncol. 2018;25(2):542-9.

100 Yang XR, Xu Y, Shi GM, Fan J, Zhou J, Ji Y, et al. Cytokeratin 10 and cytokeratin 19: predictive markers for poor prognosis in hepatocellular carcinoma patients after curative resection. Clin Cancer Res. 2008;14(12):3850-9.

101 Zen C, Zen Y, Mitry RR, Corbeil D, Karbanová J, O'Grady J, et al. Mixed phenotype hepatocellular carcinoma after transarterial chemoembolization and liver transplantation. Liver Transpl. 2011;17(8):943-54.

102 Zeng Z, Ren J, O’Neil M, Zhao J, Bridges B, Cox J, et al. Impact of stem cell marker expression on recurrence of TACE-treated hepatocellular carcinoma post liver transplantation. BMC cancer. 2012;12:584.

103 Lai JP, Conley A, Knudsen BS, Guindi M. Hypoxia after transarterial chemoembolization may trigger a progenitor cell phenotype in hepatocellular carcinoma. Histopathology. 2015;67(4):442-50.

104 Keith B, Simon MC. Hypoxia-inducible factors, stem cells, and cancer. Cell. 2007;129(3):465-72.

105 Ueshima E, Nishiofuku H, Takaki H, Hirata Y, Kodama H, Tanaka T, et al. Hepatic artery embolization induces the local overexpression of transforming growth factor $\beta 1$ in a rat hepatoma model. Liver cancer. 2020;9(1): $63-72$.

106 Ikemoto T, Shimada M, Yamada S. Pathophysiology of recurrent hepatocellular carcinoma after radiofrequency ablation. Hepatol Res. 2017;47(1):23-30.

107 Yoshida S, Kornek M, Ikenaga N, Schmelzle M, Masuzaki R, Csizmadia E, et al. Sublethal heat treatment promotes epithelial-mesenchymal transition and enhances the malignant potential of hepatocellular carcinoma. Hepatology. 2013;58(5):1667-80.

108 Tovar V, Cornella H, Moeini A, Vidal S, Hoshida Y, Sia D, et al. Tumour initiating cells and IGF/FGF signalling contribute to sorafenib resistance in hepatocellular carcinoma. Gut. 2017;66(3):530-40.

109 Zhu YJ, Zheng B, Wang HY, Chen L. New knowledge of the mechanisms of sorafenib resistance in liver cancer. Acta Pharmacol Sin. 2017;38(5):614-22.

110 Caruso S, Calatayud AL, Pilet J, La Bella T, Rekik S, Imbeaud S. Analysis of liver cancer cell lines identifies agents with likely efficacy against hepatocellular carcinoma and markers of response. Gastroenterology. 2019; 157(3):760-76.

111 El-Khoueiry AB, Sangro B, Yau T, Crocenzi TS, Kudo M, Hsu C, et al. Nivolumab in patients with advanced hepatocellular carcinoma (CheckMate 040): an open-label, non-comparative, phase 1/2 dose escalation and expansion trial. Lancet. 2017;389(10088):2492-502.

112 Zhu AX, Finn RS, Edeline J, Cattan S, Ogasawara S, Palmer D. Pembrolizumab in patients with advanced hepatocellular carcinoma previously treated with sorafenib (KEYNOTE-224): a non-randomised, open-label phase 2 trial. Lancet Oncol. 2018;19(7):940-52.

113 Li JH, Ma WJ, Wang GG, Jiang X, Chen X, Wu L, et al. Clinicopathologic significance and prognostic value of programmed cell death ligand 1 (PD-L1) in patients with hepatocellular carcinoma: a meta-analysis. Front Immunol. 2018;9:2077.

114 Pinato DJ, Mauri FA, Spina P, Cain O, Siddique A, Goldin R, et al. Clinical implications of heterogeneity in PD-L1 immunohistochemical detection in hepatocellular carcinoma: the blueprint-HCC study. Br J Cancer. 2019; 120(11):1033-6.

115 Calderaro J, Rousseau B, Amaddeo G, Mercey M, Charpy C, Costentin C, et al. Programmed death ligand 1 expression in hepatocellular carcinoma: relationship with clinical and pathological features. Hepatology. 2016;64(6):2038-46. 